\title{
Identification of Carbonium and Carbenium Ions by QTAIM
}

\author{
Caio L. Firme,* O. A. C. Antunes and Pierre M. Esteves \\ Instituto de Química, Universidade Federal do Rio de Janeiro, CT Bloco A, $6^{\circ}$ andar, \\ Cidade Universitária, Ilha do Fundão, 21941-909 Rio de Janeiro-RJ, Brazil
}

\begin{abstract}
A ferramenta de Gassman-Fentiman da demanda crescente de elétrons foi usada para identificar íons carbênios e íons carbônios. Contudo, devido ao seu entendimento ambíguo, ela foi pivô de uma disputa histórica. Nós aplicamos a metodologia da Teoria Quântica de Átomos em Moléculas - QTAIM - para caracterizar íons carbênios e íons carbônios de uma forma mais eficaz e mais fácil. Essa metodologia pode ser usada para avaliar se um carbocátion é clássico ou não. Além disso, é possível classificar um conjunto de íon carbônio na ordem de magnitude da deslocalização $\sigma$, ou $\pi$. Há poucas diferenças entre os resultados de nosso modelo baseado na QTAIM e da ferramenta de Gassman-Fentiman. Contudo, diferentemente da ferramenta de Gassman-Fentiman, os cátions 7-anisol-7-norbornenila e 2-anisol-2-norbornila são não-clássicos, embora sejam os menos íons não-clássicos em seus conjuntos correspondentes de cátions estudados.
\end{abstract}

The Gassman-Fentiman tool of increasing electron demand was used to identify carbonium and carbenium ions. Nonetheless, due to its ambiguous understanding, it was pivot of a historical dispute. We applied the Quantum Theory of Atoms in Molecules (QTAIM) metodology to characterize the carbonium and carbenium ions on an easier and more effective way. By comparing selected topological information of reference carbenium ions the QTAIM metodology can be used to evaluate whether a carbocation is classical or not. In addition, it is possible to rank a set of carbonium ions in order of their corresponding $\sigma$ or $\pi$ delocalization. There are few differences between our QTAIM-based model and Gassman-Fentiman tool. Unlike Gassman-Fentiman tool results, 7-anisyl-7-norbornenyl and 2-anisyl-2-norbornyl cations are non-classical, although they are the least nonclassical ions in their corresponding set of studied cations.

Keywords: norbornyl cation, norbornenyl cation, QTAIM, carbonium ion, carbenium ion

\section{Introduction}

In 1949 Winstein and Trifan ${ }^{1,2}$ postulated the assistance of $\sigma$ electron delocalization to account for the large rate differences in acetolysis of exo- and endo-2-norbornyl brosilates. On the other hand, Brown ${ }^{3,4}$ attributed these differences to steric effects. Thereafter, heated debates on nature of norbornyl cation, named the nonclassical ion controversy, took place. ${ }^{3-5}$ Nonetheless, experimental evidences ${ }^{6-9}$ indicated that norbornyl cation had no trivalent carbenium center characteristic of a classical ion. Eventually, the nonclassical nature ${ }^{10}$ of the hypercoordinate norbornyl cation, characterized by delocalized $\sigma$ electrons in a threecenter two-electron (3c-2e) bonding, was proved. ${ }^{11}$

Carbenium and carbonium ions, formerly named classical and nonclassical ions, respectively, can be

*e-mail: cfirme@iq.ufrj.br ; firme.caio@gmail.com identified by an index developed by Schleyer and collaborators ${ }^{12}$ based on the total ${ }^{13} \mathrm{C}$ NMR chemical shift difference between a carbocation and the corresponding neutral hydrocarbon. In the classical trivalent carbocations the chemical shift difference, $\Delta \delta$, is more than $350 \mathrm{ppm}$ while in nonclassical carbocations $\Delta \delta<100 \mathrm{ppm}$.

Gassman and Fentiman ${ }^{13,14}$ showed that the classical or nonclassical nature of the 7-aryl-p-substituted-7-norborenyl cation is dependent on the electron-withdrawing/-donating capacity of the $p$-substituent group of the aryl moiety. The corresponding ${ }^{1} \mathrm{H}$ NMR study of hydrogen atoms of the aryl moiety of these cations demonstrated that the 7-p-anisyl-7-norbornenyl cation is a carbenium ion. ${ }^{15}$ The Gassman-Fentiman tool of increasing electron demand was applied to confirm the onset of $\pi$ participation in the 2-aryl5-norbornen-2-yl system ${ }^{16}$ and the onset $\pi \sigma$ participation in 9-aryl-9-pentacyclo[4.3.0.0.0.] nonyl system. ${ }^{17}$ This tool was also used to show that there is no $\sigma$ participation in 
the 2-aryl-2-norbornyl system. ${ }^{18-21}$ Nonetheless, Olah and collaborators do demonstrate $\sigma$ participation in the 2-aryl2-norbornyl cations. ${ }^{22-24}$

Another ${ }^{1} \mathrm{H}$ NMR study of hydrogen atoms of the norbornyl moiety of several 2-aryl-2-norbornyl cations ${ }^{25}$ indicated the onset of carbonium ions by varying the nature of substituents on the phenyl ring. Olah et al. ${ }^{23}$ applied the same method by using ${ }^{13} \mathrm{CNMR}$ spectroscopy and showing that it is more reliable than the former. ${ }^{22,26}$ Furthermore, similar studies were performed with cyclopropyl, allyl and propargyl groups. ${ }^{27}$ Olah et al. ${ }^{22}$ argued that the NMR study of the increasing electron demand is useful to determine the onset of $\pi, \pi \sigma, \sigma$-delocalization provided no alternative explanation exists. Nonetheless, if the structural changes of the studied species during its solvolysis are limited, the Gassman-Fentiman tool may be considered ineffective. ${ }^{28}$

The quantum theory of atoms in molecules (QTAIM) was used to study many carbonium ions, such as proponium and 2-norbornyl cations. ${ }^{29-39}$ In this work we show that the QTAIM can be used to evaluate whether a carbocation is classical or not. It is also possible to determine the order of $\sigma$ or $\pi$ delocalization within the similar group of cations.

\section{Computational Methods}

The geometries of the studied species were optimized by using standard techniques. ${ }^{40}$ Vibrational analyses on the optimized geometries of selected points on the potential energy surface were carried out to determine whether the resulting geometries are true minima or transition states, by checking the existence of imaginary frequencies. Calculations were performed at B3LYP/6-311++G** level ${ }^{41-44}$ by using Gaussian 03 package. ${ }^{45}$ Electronic density was obtained at B3LYP/6-311++G** level for further QTAIM calculations. Charge density of the critical points, ellipticity, atomic charge, atomic dipole moment and delocalization index ${ }^{29,46-48}$ were calculated by means of AIM2000 software. $^{49}$

\section{Rationale}

The use of the Gassman-Fentiman tool of increasing electron demand has led to scientific conflict in the past. ${ }^{18-24}$ A careful choice of the parameters is necessary for a judicious application of this method. Its main idea is related to the linearity and the deviation of this linearity in a given parameter applied to a set of similar molecular systems. The molecular system which deviates from the Gassman-Fentiman linearity is probably operating on a different mechanism which is not common to all other systems. ${ }^{22}$ This principle does not state that, if a deviation is not found, the mechanism is not operating. Nor does it state that if two systems show the same deviations the same mechanism must be operating in both cases. Thus, the Gassman-Fentiman tool of increasing electron demand lacks precision, reliability and consensus. The QTAIM study of the electronic nature of these cations does not require the comparison between different parameters for a large group of similar molecular systems. The analysis of the electronic characteristics of the ions is individual. It depends only on a simple comparison of determined electronic parameters between known classical ions and the studied ions. These parameters are the delocalization index, the atomic charge, the QTAIM bond order, the ellipticity and the atomic dipole moment (See supplementary material).

The delocalization index (DI) is a measure of number of electrons that are shared or exchanged between two atomic basins from integration of the Fermi hole density through a pair density matrix. ${ }^{47,50-54}$ The B3LYP functional has an exchange-correlation contribution from Slater determinant and the exchange-correlation potential-energy density. ${ }^{41}$ Then, the density matrices of the density functional theory (DFT) yield similar results to post-Hartree-Fock theories like MP2 (see Supplementary Information). It is important to emphasize that the delocalization index does not measure the delocalization of valence electrons over the whole molecular system. It is also important to remark that the sum of all localization indexes and half DI's (because each atomic pair has the same DI) yields the total population of the molecular system. ${ }^{47,50-54}$ The delocalization index of very weak CC interactions lies between $10^{-2}$ and $10^{-3}$ order of magnitude. The DI value of $10^{-1}$ order of magnitude for CC bonds is characteristic of moderate CC interactions (See Supplementary Information).

The ellipticity $(\varepsilon)$ in a BCP is derived from the relationship between the $\lambda_{1}$ and $\lambda_{2}$ eigenvalues of the Hessian of electron density $(\rho)$. Its increase is a measure of how the electron density distribution is distorted from the axial symmetry of the bond. As $\varepsilon$ approaches to zero, the bond tends to be single or triple, i.e., completely symmetrical to interatomic axis..$^{29,46-48}$ The QTAIM bond order ${ }^{30,55}$ is obtained from its relation with the charge density in the $\mathrm{BCP}\left(\rho_{\mathrm{b}}\right)$ of the corresponding $\mathrm{CC}$ bond $\left\{\mathrm{n}=\exp \left[\mathrm{A}\left(\rho_{\mathrm{b}}-\mathrm{B}\right)\right]\right\}$. The atomic dipole moment $\left[\mathrm{M}_{1}(\Omega)\right]$ measures the magnitude and direction of the electron cloud of the atom in relation with its nucleus.

In the first part of the Results and Discussion section we intend to find reference carbenium ions by comparing their topological characteristics with a well-known carbenium ion. Thereafter, selected topological information of the reference carbenium ions will be compared with those from their corresponding parents to classify their classical or non-classical nature. 


\section{Results and Discussion}

Scheme 1 shows the studied molecular systems.

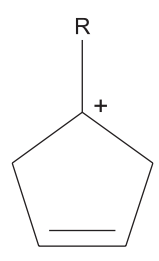

1. $\mathrm{R}=-\mathrm{H}$

2. $\mathrm{R}=-\mathrm{Ph}$

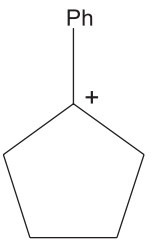

3

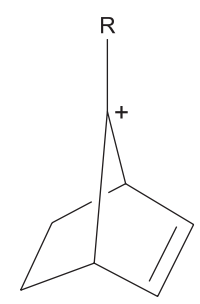

4. $\mathrm{R}=-\mathrm{Ph}$

5. $\mathrm{R}=-\mathrm{Ph}-p-\mathrm{OCH}$

6. $\mathrm{R}=-\mathrm{Ph}-p-\mathrm{CF}_{3}$

Scheme 1

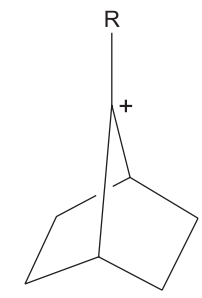

7. $\mathrm{R}=-\mathrm{H}$

8. $\mathrm{R}=-\mathrm{Ph}$ 9. $\mathrm{R}=-\mathrm{Ph}-p-\mathrm{CF}_{3}$

\section{Reference carbenium ions}

The cyclopentenyl cation $\mathbf{1}$ is a well known carbenium ion. ${ }^{28,56}$ It has no $3 \mathrm{c}-2 \mathrm{e}$ bonding system and no homoconjugative interactions. Let us compare some topological information of the cation 1 with cyclopentene. The ellipticity $(\varepsilon)$, bond length and bond order of the double bond (C2-C3 bond) of cyclopentene and cation $\mathbf{1}$ are very similar. The DI's of C1-C2 and C1-C3 atomic pairs also are very similar between cyclopentene and the cation 1 (Figure 1). Thus, from QTAIM, one can see that cyclopentenyl cation 1 does not have $\pi$ delocalization from $\mathrm{C} 2-\mathrm{C} 3$ bond.

To evaluate the classical or non-classical nature of the cation 2 it is needed to compare some of its topological information with the cation $\mathbf{1}$. The magnitude of the atomic dipole moment of $\mathrm{C} 2$ and $\mathrm{C} 3$ atoms in $\mathbf{1}$ and $\mathbf{2}$ are very similar but higher than those from the cyclopentene because of the positive charge in $\mathbf{1}$ and $\mathbf{2}$. The ellipticity $(\varepsilon)$, bond length, delocalization index and bond order of the double bond (C2-C3 bond) of the cations $\mathbf{1}$ and $\mathbf{2}$ also are very similar (Figure 1). Figure 2 shows the components of the atomic dipole moment, $\mathrm{M}_{1}(\Omega)$, of the carbon atoms $\mathrm{C} 1$ and $\mathrm{C} 2$ of the species $\mathbf{1}$ and $\mathbf{2}$. The set of values and signs of $\mathrm{M}_{1}(\mathrm{C} 2)_{\mathrm{X}}, \mathrm{M}_{1}(\mathrm{C} 2)_{\mathrm{Y}}, \mathrm{M}_{1}(\mathrm{C} 2)_{\mathrm{Z}}$ of $\mathbf{1}$ and $\mathbf{2}$ indicate that $\mathrm{M}_{1}(\mathrm{C} 2)$ points towards $\mathrm{C} 1$ atom in both species. Except for the magnitude of $\mathrm{M}_{1}(\mathrm{C} 1)$, all other selected topological information between $\mathbf{1}$ and $\mathbf{2}$ are very similar. Thus, one can assume that the cation $\mathbf{2}$ is non-classical. Hereafter, the cation 2 will be used as reference of carbenium ion. Some of its electronic features will be compared to the set of the cations $\mathbf{4}$ to $\mathbf{6}$ so as to verify their classical or nonclassical nature.

To investigate the classical or non-classical nature of the cation $\mathbf{3}$, it is not necessary to compare it with other carbenium ion. The values of DI of the C1-C3 and C1-C2 atomic pairs are very small $\left(10^{-2}\right.$ order of magnitude) and they are equivalent to very weak CC interactions. The DI and bond order of $\mathrm{C} 2-\mathrm{C} 3$ bond are similar to those from a single $\mathrm{CC}$ bond. Thus, the cation $\mathbf{3}$ has no $\sigma$ delocalization and it can be regarded as a carbenium ion as well. The cation 3 also will be used as a reference of carbenium ion in the comparison with the cations 7 to 9 .

Investigation of classical or non-classical nature of the species 4 to 9

Figure 3 depicts some geometrical and electronic parameters of the cations 4,5 and 6. The ellipticity, bond order and delocalization index of the $\mathrm{C} 2-\mathrm{C} 3$ bond

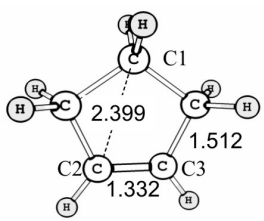

Cyclopentene

$\mathrm{M}_{1}(\mathrm{C} 2)=0.122$ $\mathrm{M}_{1}(\mathrm{C} 3)=0.121$ $\varepsilon(\mathrm{C} 2-\mathrm{C} 3)=0.36$ $\mathrm{DI}(\mathrm{C} 2-\mathrm{C} 3)=1.770$ $\mathrm{DI}(\mathrm{C} 2-\mathrm{C} 1)=0.056$ $n(\mathrm{C} 2-\mathrm{C} 3)=1.99$

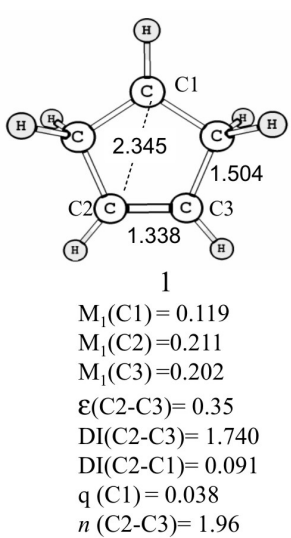

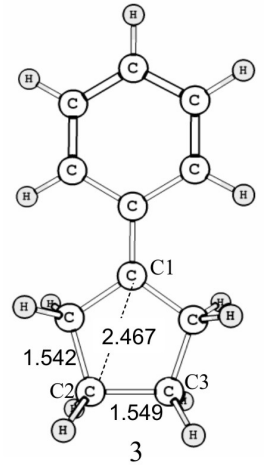

$\mathrm{M}_{1}(\mathrm{C} 1)=0.028$ $\mathrm{M}_{1}(\mathrm{C} 2)=0.098$ $\mathrm{DI}(\mathrm{C} 2-\mathrm{C} 1)=0.050$ $\mathrm{DI}(\mathrm{C} 1-\mathrm{C} 3)=0.050$ $\mathrm{DI}(\mathrm{C} 2-\mathrm{C} 3)=0.970$ $\mathrm{q}(\mathrm{C} 1)=0.023$ $n(\mathrm{C} 2-\mathrm{C} 3)=1.01$

Figure 1. The ellipticity $(\varepsilon)$, the delocalization index $(\mathrm{DI})$, the atomic dipole moment $\left[\mathrm{M}_{1}(\Omega)\right]$ in au, the atomic charge $[\mathrm{q}(\Omega)]$ in au, the bond lengths and the interatomic distances (in Angstroms) of cyclopentene and the cations 1 and 2. Dashed lines represent interatomic distance. 


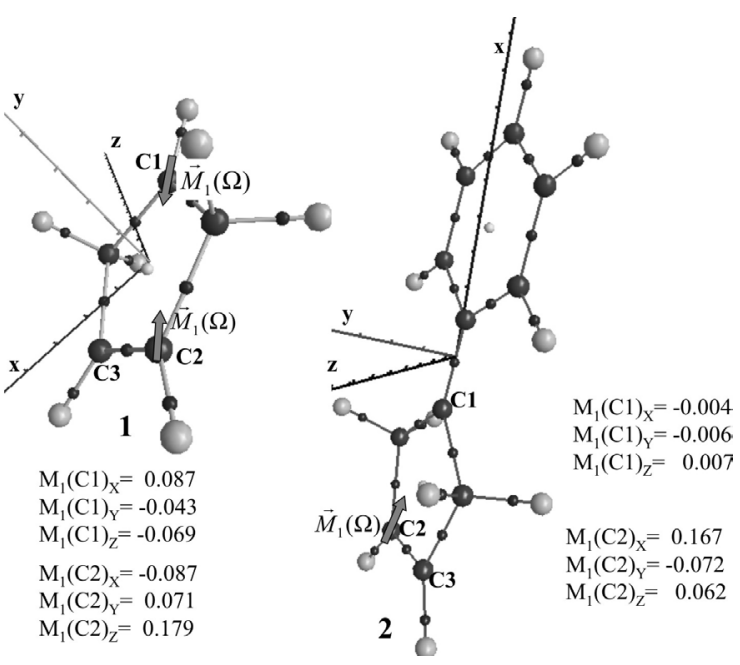

Figure 2. Molecular graph and the components of the atomic moments of carbon atoms $\mathrm{C} 1$ and $\mathrm{C} 2$, in au., of the cations $\mathbf{1}$ and $\mathbf{2}$. Pictorial representation of $M_{1}(\Omega)$ vector is also shown in $\mathrm{C} 1$ and $\mathrm{C} 2$ atoms.

in the cations $\mathbf{4}$ to $\mathbf{6}$ are smaller than those from cation 2. On the other hand, the DI's of the C1-C2 and C1-C3 atomic pairs are significantly higher than those from cation 2 . All of these information indicate that there is a $\pi$ delocalization in cations 4 to $\mathbf{6}$. Nonetheless, they do not have the same level of $\pi$ delocalization. In Figure 4 , the set of values and signs of the components of $\mathrm{M}_{1}(\Omega)$ in the $\mathrm{C} 1$ and $\mathrm{C} 2$ atoms of $\mathbf{4}$ and $\mathbf{6}$ indicate that $\mathrm{M}_{1}(\mathrm{C} 1)$ points towards $\mathrm{C} 3-\mathrm{C} 2$ bond and $\mathrm{M}_{1}(\mathrm{C} 2)$ points towards $\mathrm{C} 1$ atom. The electronic nature of the substituent in $\mathrm{C} 1$ determines how delocalized will be the $\pi$ electrons of the norbornenyl moiety. In Figure 3, one can observe a direct relation between the atomic dipole moment of $\mathrm{C} 1$ and the DI's of $\mathrm{C} 1-\mathrm{C} 2$ and $\mathrm{C} 1-\mathrm{C} 3$ atomic pairs. The higher the $\mathrm{M}_{1}(\mathrm{C} 1)$ the higher DI $(\mathrm{C} 1-\mathrm{C} 2)$ and DI $(\mathrm{C} 1-$ C3). From these results, one can say that the order of $\pi$ delocalization in these cations is $\mathbf{6}>\mathbf{4}>\mathbf{5}$. Since nonclassical ions are characterized by delocalization of $\sigma$, $\pi$ or $\sigma \pi$ electrons, one can say that the cations $\mathbf{4}$ to $\mathbf{6}$ are non-classical ions. Even the cation $\mathbf{5}$ is a non-classical ion because its electronic features are very different from those from the classical ion $\mathbf{2}$. However, the cation $\mathbf{5}$ is the least non-classic of its set of similar ions.

Figure 5 depicts the delocalization index, the atomic charge, the ellipticity, the bond order, the bond lengths and the interatomic distances of the cations 7 to 9 . The values of the bond order and delocalization index of $\mathrm{C} 2-\mathrm{C} 3$ bond in the cations 7 to 9 are significantly smaller than those from a single $\mathrm{CC}$ bond. On the other hand, the values of the bond order and delocalization index of $\mathrm{C} 1-\mathrm{C} 2$ bond in the cations 7 to 9 are higher than those from a single CC bond.

The delocalization index of the $\mathrm{C} 1-\mathrm{C} 3$ atomic pair in $\mathbf{7}$ to 9 is considerably higher than that from cation $\mathbf{3}$. The
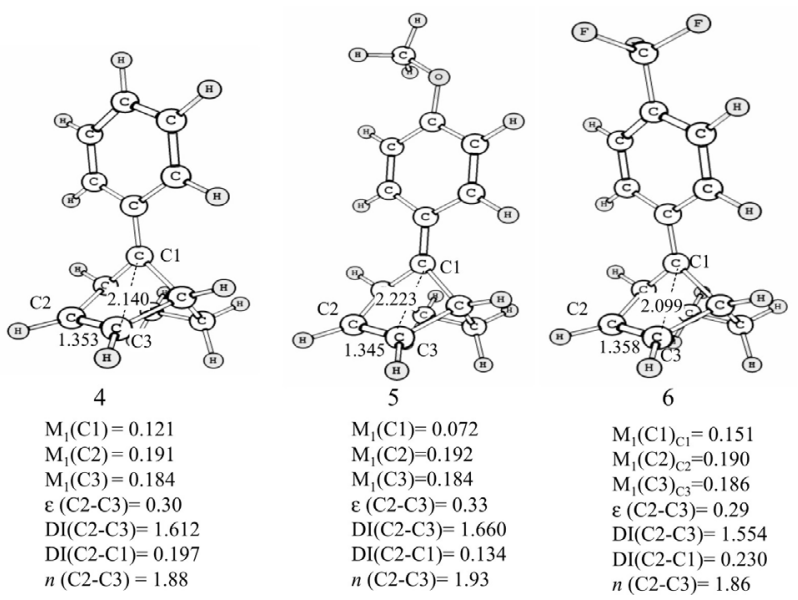

Figure 3. Selected ellipticity $(\varepsilon)$, delocalization indexes (DI), atomic dipole moment $\left[\mathrm{M}_{1}(\Omega)\right]$ in au, bond order $(n)$, bond lengths and interatomic distances (in Angstroms) of the cations 4, 5 and 6. Dashed lines represent interatomic distance.

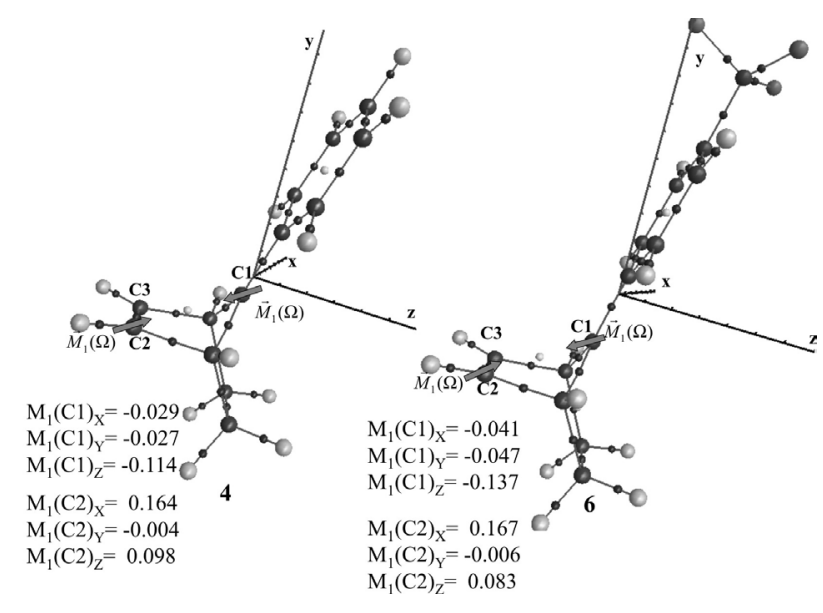

Figure 4. Molecular graph and the components of the atomic moments of carbon atoms $\mathrm{C} 1$ and $\mathrm{C} 2$, in au, of the cations $\mathbf{4}$ and $\mathbf{6}$. Pictorial representation of $\mathrm{M}_{1}(\Omega)$ vector is also shown in $\mathrm{C} 1$ and $\mathrm{C} 2$ atoms.

values of DI (C1-C3) of the cations 7 to 9 are equivalent to the DI value from a moderate $\mathrm{CC}$ chemical interaction.

In addition, the ellipticities of $\mathrm{C} 2-\mathrm{C} 3$ and $\mathrm{C} 1-\mathrm{C} 2$ bonds of the cations 7 to 9 are higher than that from a single $\mathrm{CC}$ bond. The ellipticity of $\mathrm{C} 1-\mathrm{C} 2$ bond is twice higher than the ellipticity of C2-C3 bond of all cations 7 to 9 .

All of these information indicate that there is a $\sigma$-delocalization from $\mathrm{C} 2-\mathrm{C} 3$ bond in these cations. According to the values of DI and bond order involving $\mathrm{C} 1$, $\mathrm{C} 2$ and $\mathrm{C} 3$ atoms in 7 to 9 , one can observe the following order of $\sigma$-delocalization in these cations: $9>8>7$.

The cations with anisyl substituent (5 and 8 ) are the least nonclassical ion in its corresponding set of carbonium ions. Nonetheless, they can be regarded as non-classical ions unlike the Gassman-Fentiman tool prediction about them. 


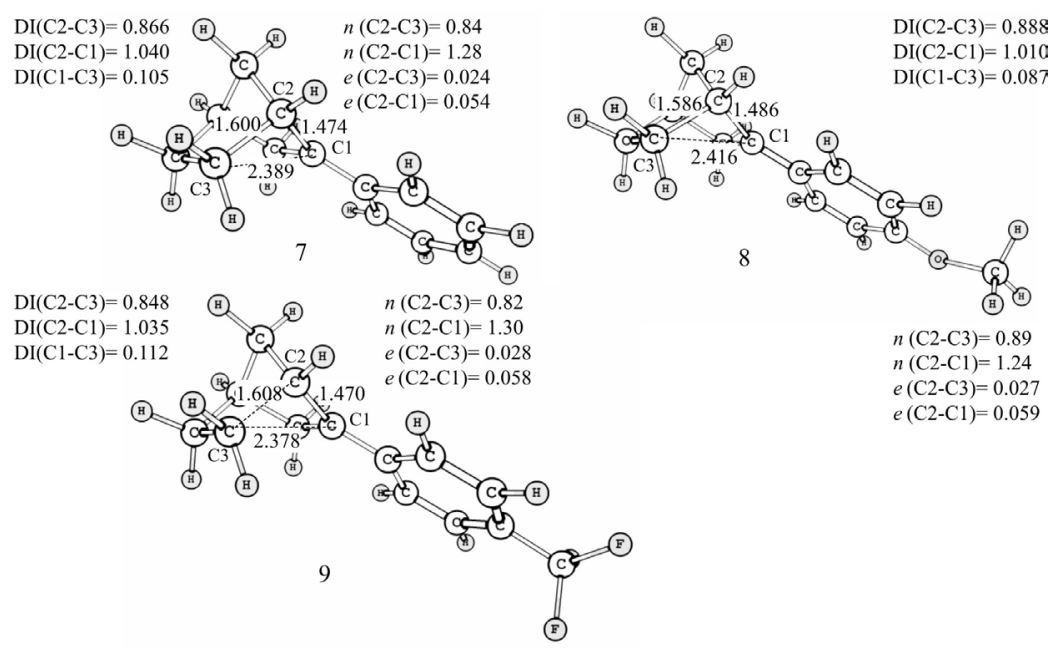

Figure 5. Selected delocalization index (DI), the atomic charge $[\mathrm{q}(\Omega)]$ in au, bond order $(n)$, ellipticity $(\varepsilon)$, the bond lengths and the interatomic distances (in Angstroms) of the cations 7 to $\mathbf{9}$. Dashed lines represent interatomic distance.

We found small differences between our QTAIM model and Gassman-Fentiman tool. Unlike Olah and collaborators' study, ${ }^{23}$ 2-anisyl-2-norbornyl cation is not a classical ion in our QTAIM model. However, it is the least non-classical ion of its studied series in gas phase. Probably, this difference can be accounted for by the influence of solvent effects in the Gassman-Fentiman tool.

\section{Conclusions}

QTAIM can be used to evaluate whether a determined cation is classical or not. The comparison of electronic parameters between a reference classical ion and the studied ion represents an easier and more effective way to classify a determined cation. This methodology affords to rank a determined set of carbonium ions in order of the magnitude of the $\sigma$, or $\pi$ delocalization. We found small differences between our QTAIM-based model and Gassman-Fentiman tool. Unlike Gassman-Fentiman tool results, 7-anisyl-7-norbornenyl and 2-anisyl-2-norbornyl cations are non-classical, although they are the least non-classical ions in their corresponding set of studied cations.

\section{Acknowledgments}

Authors thank CNPq, CAPES and FAPERJ for financial support.

\section{Supplementary Information}

This supplementary material shows the delocalization indexes of carbon atoms in trishomocyclopropenyl cation and cyclopentadiene; bond order in QTAIM, bond order and delocalization index, relation between bond order and charge density, comparison of delocalization indexes between MP2 and B3LYP, computed energy values of species $\mathbf{1}$ to $\mathbf{9}$ and $\mathrm{Z}$ matrices of the optimized structures. Total energies and geometry coordinates are also included. This material is available free of charge via the Internet at http://jbcs.sbq.org.br, as PDF file.

\section{References}

1. Winstein, S.; Trifan, D.; J. Am. Chem. Soc. 1952, 74, 1147.

2. Winstein, S.; Trifan, D. S.; J. Am. Chem. Soc. 1949, 71, 2953.

3. Brown, H. C.; Acc. Chem. Res. 1973, 6, 377.

4. Brown, H. C.; Schleyer, P. V. R.; The Nonclassical Ion Problem; Plenum Press: New York, 1977.

5. Olah, G. A.; Acc. Chem. Res. 1976, 9, 41.

6. Johnson, S. A.; Clark, D. T.; J. Am. Chem. Soc. 1988, 110, 4112.

7. Olah, G. A.; Mateescu, G. D.; Wilson, L. A.; Gross, M. H.; J. Am. Chem. Soc. 1970, 92, 7231.

8. Olah, G. A.; White, A. M.; Demember, J. R.; Commeyra.A; Lui, C. Y.; J. Am. Chem. Soc. 1970, 92, 4627.

9. Olah, G. A.; Prakash, G. K. S.; Arvanaghi, M.; Anet, F. A. L.; J. Am. Chem. Soc. 1982, 104, 7105.

10. Roberts, J. D.; Mazur, R. H.; J. Am. Chem. Soc. 1951, 73, 3542.

11. Olah, G. A.; Prakash, G. K. S.; Saunders, M.; Acc. Chem. Res. 1983, 16, 440.

12. Schleyer, P. V.; Lenoir, D.; Mison, P.; Liang, G.; Prakash, G. K. S.; Olah, G. A.; J. Am. Chem. Soc. 1980, 102, 683.

13. Gassman, P. G.; Fentiman, A. F.; J. Am. Chem. Soc. 1969, 91, 1545.

14. Gassman, P. G.; Fentiman, A. F.; J. Am. Chem. Soc. 1970, 92, 2549. 
15. Richey, H. G.; Nichols, J. D.; Gassman, P. G.; Fentiman, A. F.; Winstein, S.; Brookhar, M.; Lustgarten, R. K.; J. Am. Chem. Soc. 1970, 92, 3783.

16. Brown, H. C.; Peters, E. N.; Ravindranathan, M.; J. Am. Chem. Soc. 1975, 97, 2900.

17. Coates, R. M.; Fretz, E. R.; J. Am. Chem. Soc. 1975, 97, 2538.

18. Brown, H. C.; Ravindranathan, M.; Takeuchi, K. I.; Peters, E. N.; J. Am. Chem. Soc. 1975, 97, 2899.

19. Brown, H. C.; Takeuchi, K.; J. Am. Chem. Soc. 1968, 90, 2691.

20. Brown, H. C.; Kelly, D. P.; Periasamy, M.; J. Org. Chem. 1981, 46, 3170.

21. Brown, H. C.; Periasamy, M.; Kelly, D. P.; Giansiracusa, J. J.; J. Org. Chem. 1982, 47, 2089.

22. Olah, G. A.; Prakash, G. K. S.; Farnum, D. G.; Clausen, T. P.; J. Org. Chem. 1983, 48, 2146.

23. Olah, G. A.; Prakash, G. K. S.; Liang, G.; J. Am. Chem. Soc. 1977, 99, 5683.

24. Olah, G. A.; Berrier, A. L.; Prakash, G. K. S.; J. Org. Chem. 1982, 47, 3903.

25. Farnum, D. G.; Wolf, A. D.; J. Am. Chem. Soc. 1974, 96, 5166.

26. Farnum, D. G.; Botto, R. E.; Chambers, W. T.; Lam, B.; J. Am. Chem. Soc. 1978, 100, 3847.

27. Prakash, G. K. S.; Krishnamurthy, V. V.; Olah, G. A.; Farnum, D. G.; J. Am. Chem. Soc. 1985, 107, 3928.

28. Olah, G. A.; Berrier, A. L.; Arvanaghi, M.; Prakash, G. K. S.; J. Am. Chem. Soc. 1981, 103, 1122.

29. Bader, R. F. W.; Acc. Chem. Res. 1985, 18, 9.

30. Bader, R. F. W.; Slee, T. S.; Cremer, D.; Kraka, E.; J. Am. Chem. Soc. 1983, 105, 5061.

31. Firme, C. L.; Antunes, O. A. C.; Esteves, P. M.; J. Phys. Chem. A 2008, 112, 3165.

32. Okulik, N.; Peruchena, N.; Esteves, P. M.; Mota, C.; Jubert, A. H.; J. Phys. Chem. A 2000, 104, 7586.

33. Okulik, N.; Peruchena, N. M.; Esteves, P. M.; Mota, C. J. A.; Jubert, A.; J. Phys. Chem. A 1999, 103, 8491.

34. Okulik, N. B.; Peruchena, N. M.; Jubert, A. H.; J. Phys. Chem. A 2006, 110, 9974.

35. Okulik, N. B.; Sosa, L. G.; Esteves, P. M.; Mota, C. J. A.; Jubert, A. H.; Peruchena, N. M.; J. Phys. Chem. A 2002, 106, 1584.

36. Werstiuk, N. H.; J. Chem. Theory Comput. 2007, 3, 2258.

37. Werstiuk, N. H.; Muchall, H. M.; J. Mol. Struct. (THEOCHEM) 1999, 463, 225.

38. Werstiuk, N. H.; Muchall, H. M.; J. Phys. Chem. A 2000, 104, 2054.

39. Werstiuk, N. H.; Wang, Y. G.; J. Phys. Chem. A 2003, 107, 9434.
40. Fletcher, R.; Practical Methods of Optimization; Wiley: New York, 1980, Vol. 1.

41. Becke, A. D.; J. Chem. Phys. 1993, 98, 1372.

42. Becke, A. D.; J. Chem. Phys. 1993, 98, 5648.

43. Lee, C.; Yang, W.; Parr, R. G.; Phys. Rev. B 1988, 37, 785.

44. Dunning, J. T. H.; J. Chem. Phys. 1989, 90, 1007.

45. Frisch, M. J.; Trucks, G. W.; Schlegel, H. B.; Scuseria, G. E.; Robb, M. A.; Cheeseman, J. R.; Zakrzewski, V. G.; Montgomery, J. A. J.; Vreven, T.; Kudin, K. N.; Burant, J. C.; Millam, J. M.; Iyengar, S. S.; Tomasi, J.; Barone, V.; Mennucci, B.; Cossi, M.; Scalmani, G.; Rega, N.; Petersson, G. A.; Nakatsuji, H.; Hada, M.; Ehara, M.; Toyota, K.; Fukuda, R.; Hasegawa, J.; Ishida, M.; Nakajima, T.; Honda, Y.; Kitao, O.; Nakai, H.; Klene, M.; Li, X.; Knox, J. E.; Hratchian, H. P.; Cross, J. B.; Adamo, C.; Jaramillo, J.; Gomperts, R.; Stratmann, R. E.; Yazyev, O.; Austin, A. J.; Cammi, R.; Pomelli, C.; Ochterski, J. W.; Ayala, P. Y.; Morokuma, K.; Voth, G. A.; Salvador, P.; Dannenberg, J. J.; Zakrzewski, V. G.; Dapprich, S.; Daniels, A. D.; Strain, M. C.; Farkas, O.; Malick, D. K.; Rabuck, A. D.; Raghavachari, K.; Foresman, J. B.; Ortiz, J. V.; Cui, Q.; Baboul, A. G.; Clifford, S.; Cioslowski, J.; Stefanov, B. B.; Liu, G.; Liashenko, A.; Piskorz, P.; Komaromi, I.; Martin, R. L.; Fox, D. J.; Keith, T.; Al-Laham, M. A.; Peng, C. Y.; Nanayakkara, A.; Challacombe, M.; Gill, P. M. W.; Johnson, B.; Chen, W.; Wong, M. W.; Gonzalez, C.; Pople, J. A.; Gaussian 03. Revision B.04; 2003.

46. Bader, R. F. W.; Chem. Rev. 1991, 91, 893.

47. Bader, R. F. W.; Atoms in Molecules: A Quantum Theory, Ed. Oxford: Oxford, 1994.

48. Popelier, P. L. A.; Atoms in Molecules: An Introduction, Prentice Hall: Manchester, 2000

49. Biegler-König, F.; Schönbohm, J.; AIM2000; Version 2.0, 2002.

50. Bader, R. F. W.; Johnson, S.; Tang, T. H.; Popelier, P. L. A.; J. Phys. Chem. 1996, 100, 15398.

51. Bader, R. F. W.; Stephens, M. E.; J. Am. Chem. Soc. 1975, 97, 7391.

52. Bader, R. F. W.; Streitwieser, A.; Neuhaus, A.; Laidig, K. E.; Speers, P.; J. Am. Chem. Soc. 1996, 118, 4959.

53. Merino, G.; Vela, A.; Heine, T.; Chem. Rev. 2005, 105, 3812.

54. Fradera, X.; Austen, M. A.; Bader, R. F. W.; J. Phys. Chem. A 1999, 103, 304.

55. Bader, R. F. W.; Tang, T. H.; Tal, Y.; Biegler-König, F. W.; J. Am. Chem. Soc. 1982, 104, 946.

56. Szabo, K. J.; Kraka, E.; Cremer, D.; J. Org. Chem. 1996, 61, 2783.

Received: May 26, 2008

Web Release Date: March 6, 2009 


\title{
Identification of Carbonium and Carbenium Ions by QTAIM
}

\author{
Caio L. Firme, * O. A. C. Antunes and Pierre M. Esteves \\ Instituto de Química, Universidade Federal do Rio de Janeiro, CT Bloco A, $6^{\circ}$ andar, \\ Cidade Universitária, Ilha do Fundão, 21941-909 Rio de Janeiro-RJ, Brazil
}

Delocalization indexes of carbon atoms in trishomocyclopropenyl cation ${ }^{l}$ and cyclopentadiene.

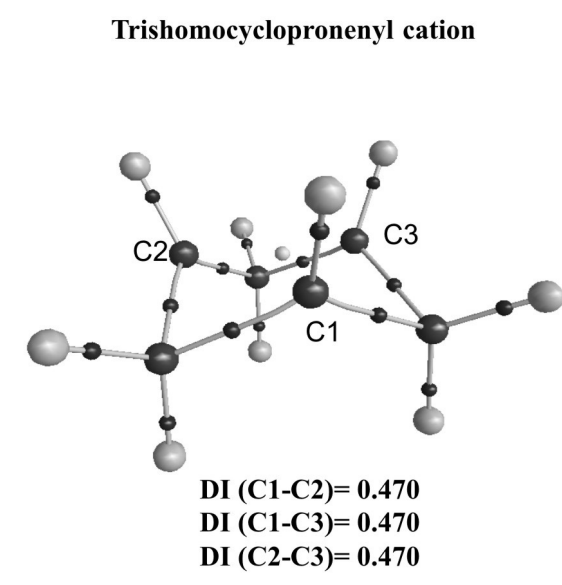

C1-C2-C3: moderate CC interactions

Bond order and delocalization index

Matta and Hernandez-Trujillo ${ }^{3}$ established a relation between the delocalization index and the bond order.

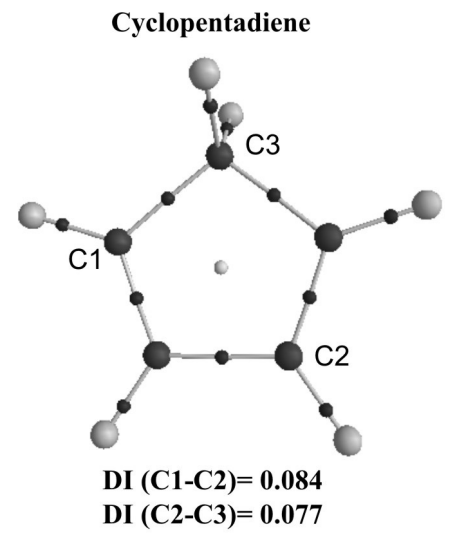

C1-C2 and C2-C3: very weak CC interactions

Table S1. Bond orders in ethane, ethylene, benzene, hexatriene and anthracene according to Ruedenberg bond order, Coulson bond order, experimental bond order and the delocalization index

\begin{tabular}{lccccc}
\hline Molecule & Bond & Ruedenberg bond order & Coulson bond order $^{\mathrm{b}}$ & Experimental bond order $^{\mathrm{c}}$ & Delocalization index $^{\mathrm{d}}$ \\
\hline Ethane & $\mathrm{C}-\mathrm{C}$ & 0.00 & - & 1.16 & 1.00 \\
Ethylene & $\mathrm{C}=\mathrm{C}$ & 1.00 & 2.00 & 1.80 & 1.99 \\
Benzene & $\mathrm{CC}$ & - & 1.66 & 1.63 & 1.39 \\
Hexatriene & $\mathrm{C}=\mathrm{C}$ & 0.85 & $1.87 / 1.78$ & - & 1.74 \\
& $\mathrm{C}-\mathrm{C}$ & 0.38 & 1.48 & - & 1.14 \\
Anthracene & $\mathrm{C}_{1}-\mathrm{C}_{2}$ & 0.70 & - & - & 1.48 \\
& $\mathrm{C}_{2}-\mathrm{C}_{3}$ & 0.49 & - & - & 1.21 \\
\hline
\end{tabular}

${ }^{\mathrm{a}}$ From Reference 4; ${ }^{\mathrm{b}}$ From Reference 5; ${ }^{\mathrm{c}}$ From Reference 2; ${ }^{\mathrm{d}}$ Calculated from B3LYP/6-311++G** level of theory.

*e-mail: cfirme@iq.ufrj.br ; firme.caio@gmail.com

Although the concept of DI is different from the Lewis concept of bond order, the former can be used to estimate the bond order of a covalent bond in an alternative way (See Table S1) 


\section{Relation between bond order and charge density}

From the relation between bond order $(n)$ and charge density in the BCP of a CC bond $\left(\rho_{\mathrm{b}}\right), n=\exp \left[A\left(\rho_{\mathrm{b}}-B\right)\right]$, a plot of the natural logarithm of bond order versus charge density of $\mathrm{CC}$ bond (Figure 1) from known values of bond order and charge density of BCP from ethane, ethylene, acetylene and benzene (Table S2) was constructed (Figure $\mathrm{S} 1$ ). The values of charge density in the bond critical points of $\mathrm{CC}$ bonds of ethane, benzene, ethylene and acetylene were obtained by B3LYP/6-311++G** level.

Table S2.: Charge density of CC bonds and natural logarithm of bond order of the corresponding $\mathrm{CC}$ bonds of ethane, benzene, ethylene and acetylene

\begin{tabular}{lcc}
\hline Molecule & $\rho_{\mathrm{b}}$ & $\ln n$ \\
\hline Ethane & 0.231 & 0 \\
Benzene & 0.309 & 0.470 \\
Ethylene & 0.344 & 0.693 \\
Acetylene & 0.412 & 1.098 \\
\hline
\end{tabular}

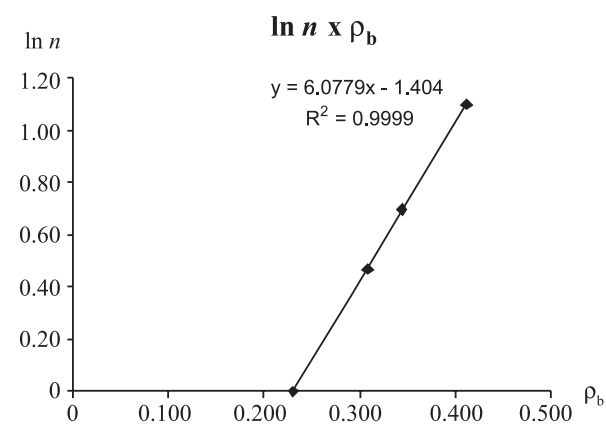

Figure S1. Natural logarithm of bond order x charge density of CC bond plot.

\section{References}

1. Firme, C. L.; Antunes, O. A. C.; Esteves, P. M.; J. Phys. Chem. A 2008, 112, 3165.

2. Jules, J. L.; Lombardi, J. R.; J. Mol. Struct. (THEOCHEM) 2003, 664, 255.

3. Matta, C. F.; Hernandez-Trujillo, J.; J. Phys. Chem. A 2003, 107, 7496

4. Ham, N. S.; Ruedenberg, K.; J. Chem. Phys. 1958, 29, 1215.

5. Coulson, C. A.; Proc. Royal Soc. London A 1939, 169, 413.

Comparison of delocalization indexes between MP2 and B3LYP

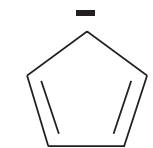

$\mathrm{DI}(\mathrm{C}-\mathrm{C})=1.379(\mathrm{~B} 3 \mathrm{LYP})$

DI $(\mathrm{C}-\mathrm{C})=1.364(\mathrm{MP} 2)$

Computed energy values of systems 1 to 9 and cyclopentene

\begin{tabular}{lccc}
\hline Entry & $\mathrm{H}($ Hartree $)$ & $\mathrm{S}\left(\mathrm{cal} \mathrm{mol}^{-1} \mathrm{~K}^{-1}\right)$ & $\mathrm{G}$ (Hartree) \\
\hline 1 & -194.342783 & 70.986 & -194.376511 \\
2 & -425.416761 & 93.573 & -425.461220 \\
3 & -426.624261 & 89.761 & -426.666910 \\
4 & -502.797730 & 99.115 & -502.844823 \\
5 & -617.335286 & 111.430 & -617.388230 \\
6 & -839.926255 & 120.742 & -839.983623 \\
7 & -504.023172 & 99.509 & -504.070452 \\
8 & -618.561144 & 111.806 & -618.614267 \\
9 & -841.151291 & 120.986 & -841.208776 \\
Cyclopentene & -195.260159 & 69.448 & -195.293156
\end{tabular}

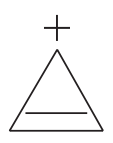

$\mathrm{DI}(\mathrm{C}-\mathrm{C})=1.437(\mathrm{~B} 3 \mathrm{LYP})$

DI $(\mathrm{C}-\mathrm{C})=1.432(\mathrm{MP} 2)$

Internal coordinates of optimized structures

Structure 1

Charge $=1$ Multiplicity $=1$

C, $0,0.0319640497,-0.1165705013,0.0365149283$

C, $0,0.1138490774,0.1965866624,1.4473079245$

C, $0,1.4387591539,-0.11676445,1.9389268773$

C, $0,2.1867708038,-0.646219493,0.746396755$

C, $0,1.3915516007,-0.6453337358,-0.3295296022$

$\mathrm{H}, 0,-0.6965298635,0.6043902691,2.0466052335$

$\mathrm{H}, 0,-0.3139606236,0.7786545606,-0.5216318108$

$\mathrm{H}, 0,1.8710739475,0.7790686748,2.4322221061$

$\mathrm{H}, 0,1.3551312288,-0.8016563921,2.8089938527$

$\mathrm{H}, 0,-0.8239769529,-0.8022051186,-0.1380366532$

$\mathrm{H}, 0,1.6484435404,-0.9685893282,-1.3281267504$

H,0,3.2166584045,-0.9699582278,0.7933532687 
Structure 2

Charge $=1$ Multiplicity $=1$

C, $0,0.1389914862,0.4919166781,0.2870062019$

C, $0,0.0637158449,-0.4217152039,1.2508833793$

C, $0,1.4320362964,-0.9143958226,1.6481969204$

C,0,2.3751555522,-0.1535790487,0.7670939294

C, $0,1.5692701967,0.7533684384,-0.1113784003$

H, $0,1.6635963137,-0.7363512234,2.7087913028$

H,0,1.5590865996,-1.9979232798,1.5079774509

H,0,1.8727801955,1.8009115226,0.0326556657

H, $0,1.7675426581,0.5438225247,-1.1727700086$

C, $0,3.7762902728,-0.271830474,0.7654683258$

C, $0,4.5738263982,0.5065372269,-0.1262997936$

C, $0,4.4331175982,-1.1744936969,1.6548625928$

C, $0,5.9472687492,0.384278458,-0.1253438325$

H,0,4.1003428111,1.1990845543,-0.8105190736

C,0,5.8071938856,-1.2890388696,1.6475184772

H,0,3.8506160756,-1.7750259293,2.3419242872

C,0,6.5638435918,-0.5117040901,0.759249906

$\mathrm{H}, 0,6.5491451601,0.9760709104,-0.8034726146$

H,0,6.3020814294,-1.975227767,2.3232150885

H,0,7.6441731707,-0.6049751897,0.7566310664

$\mathrm{H}, 0,-0.840429668,-0.7900890932,1.7156214226$

H,0,-0.6926937162,1.0039129087,-0.1770376729

Structure 3
C
C, $1, \mathrm{~B} 1$
C,2,B2,1,A1
C,3,B3,2,A2,1,D1,0
$\mathrm{C}, 4, \mathrm{~B} 4,3, \mathrm{~A} 3,2, \mathrm{D} 2,0$
$\mathrm{H}, 1, \mathrm{~B} 5,2, \mathrm{~A} 4,3, \mathrm{D} 3,0$
$\mathrm{H}, 1, \mathrm{~B} 6,2, \mathrm{~A} 5,3, \mathrm{D} 4,0$
$\mathrm{H}, 2, \mathrm{~B} 7,1, \mathrm{~A} 6,5, \mathrm{D} 5,0$
$\mathrm{H}, 2, \mathrm{~B} 8,1, \mathrm{~A} 7,5, \mathrm{D} 6,0$
H,3,B9, 2,A8, 1,D7,0
H,3,B10,2,A9, 1,D8,0
H,5,B11,4,A10,3,D9,0
H,5,B12,4,A11,3,D10,0
C,4,B13,3,A12,2,D11,0
C,14,B14,4,A13,3,D12,0
C,14,B15,4,A14,3,D13,0
C,15,B16,14,A15,4,D14,0
H, 15,B17,14,A16,4,D15,0
C, 16,B18,14,A17,4,D16,0
H,16,B19,14,A18,4,D17,0
C,19,B20,16,A19,14,D18,0

H,17,B21,15,A20,14,D19,0

H, 19,B22,16,A21,14,D20,0

H,21,B23, 19,A22,16,D21,0

Variables:

B1 $=1.54916997$

B2 $=1.54179207$

B3 $=1.50293595$

B4=1.50377255

B5=1.08972001

B6=1.09101639

$\mathrm{B} 7=1.0910065$

$\mathrm{B} 8=1.08954835$

B9 $=1.09416146$

$\mathrm{B} 10=1.09899061$

B 11 $=1.09836181$

B12 $=1.0941379$

$\mathrm{B} 13=1.40998211$

B14=1.42982174

B $15=1.43166926$

B16=1.37766245

B17=1.08119659

$\mathrm{B} 18=1.37828826$

$\mathrm{B} 19=1.08063491$

$\mathrm{B} 20=1.40173673$

B21 $=1.08251018$

B22 $=1.08257209$

B23 $=1.08466603$

$\mathrm{A} 1=106.78964547$

A2 $=108.26651082$

A3 $=109.17290882$

A4=110.93170715

A $5=111.13352678$

A6 $=110.90862154$

A $7=111.17528373$

A $8=111.61451136$

A9 $=112.78295556$

$\mathrm{A} 10=108.29526981$

A11 $=111.54882883$

$\mathrm{A} 12=125.18332048$

$\mathrm{A} 13=120.76150898$

A $14=121.49859125$

A $15=120.98161736$

A16 $=119.74157398$

A $17=121.00292024$

$\mathrm{A} 18=119.91665798$

$\mathrm{A} 19=119.45280271$

A20 $=120.64322935$

A $21=120.7151995$

A22 $=119.37542955$

D1=-7.32111319 


$$
\begin{aligned}
& \text { D2 }=3.56055099 \\
& \text { D3 }=129.18974784 \\
& \text { D4 }=-112.25870742 \\
& \text { D5 }=-112.16460935 \\
& \text { D6 }=129.28114643 \\
& \text { D7 }=114.77422199 \\
& \text { D8 }=-128.07813816 \\
& \text { D9 }=124.30883401 \\
& \text { D10 }=-121.58438324 \\
& \text { D11 }=-175.60248684 \\
& \text { D12 }=-4.59514491 \\
& \text { D13 }=175.10614424 \\
& \text { D14 }=-178.88719263 \\
& \text { D15 }=-1.53687308 \\
& \text { D16 }=-178.84584935 \\
& \text { D17 }=-1.41218403 \\
& \text { D18 }=-2.09252437 \\
& \text { D19 }=177.28697745 \\
& \text { D20 }=177.45687286 \\
& \text { D21 }=-178.94781261
\end{aligned}
$$

\section{Structure 4}

Charge $=1$ Multiplicity $=1$

C, $0,0.9921341728,0.3475202426,-0.1213362462$ C, $0,0.1421470419,0.2251274832,1.1388567634$ C, $0,2.3036649391,-0.295538475,1.6932482836$ C, $0,2.2683866522,0.039676734,0.205986329$ C, $0,1.2833451421,0.7876515049,1.9525933893$ C, $0,0.0592853535,-1.2615923077,1.5899941501$ H, $0,-0.6086994103,-1.3554992457,2.4480747424$ H, $0,-0.3390639276,-1.8826384218,0.7876918736$ C, $0,1.5251151439,-1.6144909019,1.9662882159$ $\mathrm{H}, 0,1.6137363781,-1.88976421,3.0187226021$ $\mathrm{H}, 0,1.9359370988,-2.430740171,1.3721451183$ $\mathrm{H}, 0,-0.7969800593,0.768680554,1.116204361$ $\mathrm{H}, 0,3.2794868102,-0.2127663492,2.1611610566$ $\mathrm{H}, 0,0.6231274058,0.6885303272,-1.0803192878$ $\mathrm{H}, 0,3.1399158781,0.0814915536,-0.4349181022$ C, $0,1.4068611719,2.0213639832,2.6292617439$ C, $0,0.3103315345,2.9232782101,2.6928481259$ C, $0,2.6150029445,2.3603516,3.2968557405$ C, $0,0.4249176282,4.1119321589,3.3878957223$ H, $0,-0.6208157773,2.6787109419,2.198557377$ C,0,2.7179504577,3.5513207443,3.989804217 $\mathrm{H}, 0,3.4577982392,1.6821359212,3.2670747512$ C, $0,1.6262461183,4.4264738127,4.0342168977$ $\mathrm{H}, 0,-0.4121987666,4.7970745279,3.4364631834$ $\mathrm{H}, 0,3.6384549018,3.8067386031,4.4996868975$ H, $0,1.7108090565,5.3588993863,4.5808277288$
Structure 5

Charge $=1$ Multiplicity $=1$

C, $0,-0.4681975694,-0.4237712998,0.9222196372$

C, $0,0.3483338557,-0.5592194066,2.2065634043$

C, $0,1.6523728002,0.489786886,0.6559646721$

C, $0,0.3006460532,0.1940752183,0.0083112957$

C, $0,1.05827172,0.7617468538,2.0191518644$

C, $0,1.5055388682,-1.5807532789,1.9558591147$

$\mathrm{H}, 0,2.0553680204,-1.765442863,2.8807133512$

$\mathrm{H}, 0,1.1049905685,-2.5327520729,1.6076079173$

C, $0,2.3953819093,-0.8649249435,0.8971291136$

H, $0,3.402088373,-0.6833740316,1.2785020249$

$\mathrm{H}, 0,2.4855742365,-1.4217695318,-0.0355061949$ $\mathrm{H}, 0,-0.2244016777,-0.7158671171,3.1157873574$ H, $0,2.2422223286,1.2684439657,0.1812291589$ $\mathrm{H}, 0,-1.4807769482,-0.7855968005,0.8014449583$ $\mathrm{H}, 0,0.0463710097,0.4411921595,-1.0139900175$ C, $0,1.0781023272,1.9016928976,2.8114001902$ C, $0,1.803838622,3.0654984082,2.408161608$ C, $0,0.388595459,1.9479699898,4.0681405277$ C, $0,1.843835672,4.1929546283,3.1870822277$ $\mathrm{H}, 0,2.3383559263,3.0585638861,1.466965533$ C, $0,0.4215632878,3.0662443973,4.8494418251$ H,0,-0.1671144419,1.0823419697,4.4043436844 C, $0,1.1487789602,4.2094014776,4.422911832$ $\mathrm{H}, 0,2.4033582633,5.0573124238,2.858140176$ $\mathrm{H}, 0,-0.0934692854,3.1151264334,5.8003863861$ O,0,1.1209869209,5.2370697512,5.2473252779 C, $0,1.8190492514,6.4653330279,4.9409468884$ H, $0,1.6185111128,7.1198706113,5.7841288687$ H,0,2.8913995845,6.2805425294,4.8583221012 H, $0,1.42514412,6.9062355854,4.0236745508$

Structure 6

Charge $=1$ Multiplicity $=1$

C,0,1.0610721071, $0.4166069759,-0.071976316$ C, $0,0.1488701726,0.2534514927,1.1356193083$

C, $0,2.2730507655,-0.3527734566,1.7654327682$ C, $0,2.3163997216,0.0577782192,0.300173705$

C, $0,1.2859565585,0.7688900614,1.9848701264$ C, $0,0.0076491651,-1.2416671678,1.5312431605$ $\mathrm{H}, 0,-0.7004746818,-1.3423253366,2.3555015686$ $\mathrm{H}, 0,-0.3729491891,-1.8241052393,0.6922208822$ C, $0,1.4433950272,-1.6512798492,1.9575304936$ H, $0,1.4787005451,-1.9631023664,3.0027419294$ $\mathrm{H}, 0,1.8551404048,-2.4605427283,1.354545315$ $\mathrm{H}, 0,-0.7713000489,0.8272167832,1.0939911155$ H,0,3.2285926039,-0.3134146136,2.2784750107 
$\mathrm{H}, 0,0.7586191022,0.8471945222,-1.0185404562$ $\mathrm{H}, 0,3.2213870448,0.1430767677,-0.2885224758$ C, $0,1.4388316402,2.0089212266,2.6660810182$ C, $0,0.3827852739,2.9522133366,2.6895404231$ C,0,2.6288211867,2.2944352134,3.3805516305 C, $0,0.5169506778,4.1375872838,3.3900270004$ $\mathrm{H}, 0,-0.54052027,2.7508246003,2.1623628589$ C,0,2.756926903,3.4786766536,4.0818000455 H, $0,3.4441291906,1.5831212776,3.3883810383$ C, $0,1.7023474675,4.3984712943,4.0838019972$ H, $0,-0.2927425395,4.8552003803,3.4126631315$ $\mathrm{H}, 0,3.6626535586,3.691248486,4.6353333675$ C, $0,1.8740565963,5.7157803359,4.821594728$ F,0,2.5706392741,5.5475340155,5.9576899586 F,0,2.5487253611,6.5899834288,4.0493071265 F,0,0.6908155216,6.2662271991,5.1328156356

Structure 7

Charge $=1$ Multiplicity $=1$

C, $0,-0.2249192587,0.2975928903,0.5782123199$ C, $0,0.3414220007,0.0177205026,2.0483829311$ C, $0,2.1345543001,-0.2252375254,0.6655477426$ C, $0,1.0227282807,0.1626657167,-0.3348958663$ $\mathrm{H}, 0,-1.0451777952,-0.3687560246,0.3103011172$ $\mathrm{H}, 0,-0.6197425008,1.3151360852,0.60256705$ $\mathrm{H}, 0,0.8898718222,-0.5846526351,-1.1190970286$ H, $0,1.2572075245,1.109839552,-0.8226845811$ C,0,1.7694839774,0.6104205095,1.9050682163 H, $0,2.4038203137,0.4158899468,2.7727336495$ H, $0,1.7399992368,1.6852626893,1.7214490737$ C, $0,0.5776616036,-1.4371021334,2.0112485242$ C, $0,1.8191434158,-1.6445902729,1.1922498563$ H, $0,2.616043121,-1.9686069683,1.8789713867$ H,0,1.7199108525,-2.4234537973,0.4321599361 H, $0,-0.3026587724,0.4023647165,2.833126295$ $\mathrm{H}, 0,3.1501217807,-0.1198738239,0.2896946661$ C, $0,-0.2231370518,-2.4537996284,2.5803831467$ C, $0,-1.3708282393,-2.1328377774,3.3596310874$ C, $0,0.1130063579,-3.8253298552,2.3972504388$ C, $0,-2.1398134055,-3.1340342891,3.9196185919$ H,0,-1.6465068262,-1.0985982386,3.5171917646 C,0,-0.6594549384,-4.8187282087,2.9647772885 H, $0,0.9834037029,-4.0944633054,1.8125990628$ C, $0,-1.7853629473,-4.4743736079,3.7238147984$ H, $0,-3.0119500919,-2.8851378531,4.5111633494$ $\mathrm{H}, 0,-0.3979959947,-5.8601998115,2.8252259023$ H,0,-2.390097607,-5.2572397283,4.1677090894
Structure 8

Charge $=1$ Multiplicity $=1$

C, $0,-0.3805903922,0.3313689786,0.8960151125$ C, $0,0.4554379578,-0.110628097,2.1686263362$ C,0,1.96979546,-0.0785119151,0.4709411416 C,0,0.6751721948,0.3666038115,-0.2461103875 $\mathrm{H}, 0,-1.2209848389,-0.3345606982,0.6968201233$ H, $0,-0.7874621891,1.3212153705,1.1118057117$ $\mathrm{H}, 0,0.4156689343,-0.2912460704,-1.0776642185$ $\mathrm{H}, 0,0.7845449942,1.3741175963,-0.6500314477$ C, $0,1.8151819593,0.5713345258,1.8590225491$ H,0,2.6053701899,0.3001775178,2.5629245229 $\mathrm{H}, 0,1.7235891559,1.658224494,1.8306363854$ C, $0,0.7521407888,-1.5442709697,1.9140388672$ C, $0,1.8181090051,-1.5701644592,0.8471133744$ $\mathrm{H}, 0,2.7494726298,-1.9410074172,1.2977277639$ H,0,1.5794916582,-2.236093674,0.0134659094 $\mathrm{H}, 0,-0.029837133,0.132409112,3.1098026472$ $\mathrm{H}, 0,2.889695666,0.1401080824,-0.0679419898$ C,0,0.1491118776,-2.6590711763,2.4990443782 C, $0,-0.8518513941,-2.5216382525,3.5100009921$ C,0,0.5165166873,-3.9899525343,2.1110809341 C,0,-1.4482424892,-3.6125802096,4.0893312442 $\mathrm{H}, 0,-1.1544166008,-1.5334614652,3.8310508062$ C, $0,-0.0669372927,-5.0827818855,2.683553924$ $\mathrm{H}, 0,1.2745128885,-4.1352875081,1.351883685$ C,0,-1.0619966231,-4.9140613236,3.682940792 H,0,-2.2030978997,-3.4740229303,4.8504332974 H,0,0.2050415525,-6.0914542896,2.3996464742 $\mathrm{O}, 0,-1.5658184455,-6.028978545,4.1735640743$ C,0,-2.5858691248,-6.0050086214,5.1974427917 $\mathrm{H}, 0,-3.4807795501,-5.5006953041,4.8289059249$ $\mathrm{H}, 0,-2.8045161683,-7.0493529131,5.4003442966$ $\mathrm{H}, 0,-2.2063610266,-5.5207823051,6.0988253199$

\section{Structure 9}

Charge $=1$ Multiplicity $=1$

C,0,-0.2552729898,0.3030959104,0.6646177367 C, $0,0.3950406053,0.0040445856,2.1044082294$ C, $0,2.0997791481,-0.2397397843,0.6130820368$ C, $0,0.9365051351,0.1713328419,-0.3177716972$ H,0,-1.0960897081,-0.3523820613,0.437308011 $\mathrm{H}, 0,-0.6388538748,1.3230993705,0.7315872092$ $\mathrm{H}, 0,0.753324476,-0.5631947176,-1.1036755164$ H, $0,1.1519628174,1.1237825971,-0.8040082106$ C, $0,1.8164312692,0.5847948521,1.8806857093$ H, $0,2.4989388753,0.3749675762,2.7072374316$ H, $0,1.7864061138,1.6616722746,1.7105208802$ 
C, $0,0.6024952324,-1.4488541446,2.0238575572$

C, $0,1.7942211118,-1.6616731465,1.1397463958$

$\mathrm{H}, 0,2.620428471,-1.9984466525,1.785828548$

$\mathrm{H}, 0,1.651410929,-2.4343985593,0.3804104681$

$\mathrm{H}, 0,-0.202568077,0.3869028414,2.9258210256$

$\mathrm{H}, 0,3.0935273389,-0.1432952248,0.1811391922$

C, $0,-0.1956673989,-2.4670875031,2.6091674896$

C, $0,-1.2876000513,-2.1415853541,3.4573808965$

C, $0,0.0941662822,-3.8376356088,2.3715102767$

C,0,-2.0542880905,-3.1373520614,4.0318638799

$\mathrm{H}, 0,-1.528019687,-1.107216013,3.6630689346$

C, $0,-0.6711849983,-4.830004859,2.951444797$

$\mathrm{H}, 0,0.9244332045,-4.115340136,1.7352914884$

C, $0,-1.744829702,-4.4781715501,3.7786693571$

$\mathrm{H}, 0,-2.882557017,-2.8861254915,4.6816082405$

$\mathrm{H}, 0,-0.4425273403,-5.8732615398,2.7755506646$

C, $, 0,-2.6165432993,-5.5746154133,4.3709813988$

F, $0,-1.9008078928,-6.6806664462,4.6259813068$

F, $0,-3.1976694221,-5.1771515505,5.5125789375$

F, $0,-3.5902212411,-5.9010274548,3.4992199503$
Cyclopentene

Charge $=0$ Multiplicity $=1$

C, $0,-0.9872655082,0.2142156248,-0.7106657544$

C, $0,-0.8606010785,0.487531982,0.8117462799$

C, $0,0.6086115947,0.2532872824,1.0808272007$

C, $0,1.2176628381,-0.3420404716,0.055276458$

C, $0,0.2682336702,-0.6158672192,-1.0890417527$

$\mathrm{H}, 0,-0.9679017242,1.164619311,-1.2508712578$

$\mathrm{H}, 0,-1.4725234275,-0.2060567315,1.4038871098$

$\mathrm{H}, 0,-1.1877535567,1.4960535101,1.0835890553$

$\mathrm{H}, 0,1.0830855487,0.5106190867,2.0212896963$

H, $0,2.2601668315,-0.6399395303,0.0392617525$

H, $0,0.0449894585,-1.689376153,-1.1513764809$

H,0,0.6802874335,-0.3298957167,-2.061911172

H,0,-1.9201996615,-0.2887869667,-0.9727232927 